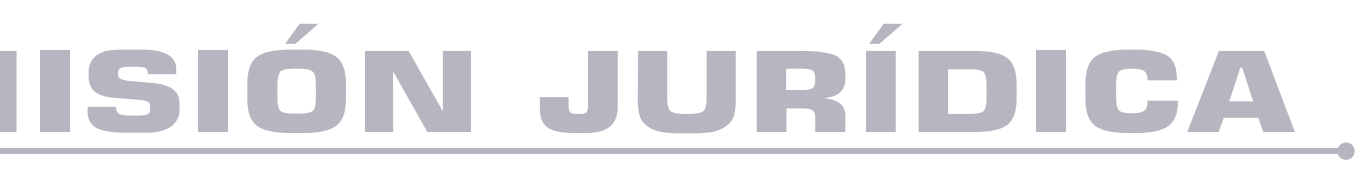

\title{
El derecho de transformación de la obra musical
}

The right of transformation of the musical work

Autor: Carmen M. García-Trelles Fernández

DOl: https://doi.org/10.25058/1794600X.1910

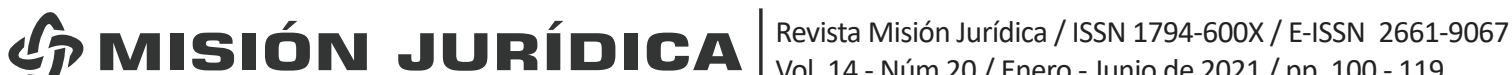




\title{
EL DERECHO DE TRANSFORMACIÓN DE LA OBRA MUSICAL*
}

\author{
The right of transformation of the musical work
}

\section{0 direito de transformar o trabalho musical}

\author{
Carmen M. García-Trelles Fernández ${ }^{\mathrm{a}}$ \\ carmentrelles@uniovi.es \\ Fecha de recepción: 22 de junio de 2020 \\ Fecha de revisión: 2 de julio de 2020 \\ Fecha de aceptación: 22 de septiembre de 2020
}

\section{RESUMEN}

DOI: https://doi.org/10.25058/1794600X.1910

Para citar este artículo:

García-Trelles, C. M. (2021). El derecho de transformación de la obra musical. Revista Misión Jurídica, 14, (20), 100 -119.

El artículo pretende dar una visión interdisciplinar de la problemática del derecho de trasformación de la obra musical original y su posible conceptuación como obra derivada. A razón del escaso tratamiento del tema que se hace por el Texto Refundido de la Ley de Propiedad Intelectual española, con frecuencia se generan conflictos cuando el autor de una composición original autoriza la incorporación de ésta en otra nueva, ostentando la facultad para que su obra se mantenga totalmente íntegra sin sufrir menoscabo o deformación, una vez que ha consentido su exhibición o explotación. Dentro del contexto jurídico y musicológico se trata de dar un enfoque transversal y establecer criterios objetivos referidos al ámbito musical que, inmersos en la legislación de propiedad intelectual, consigan dar soluciones a las dudas surgidas respecto a la coyuntura actual e intrincada de la delimitación de la transformación de las obras musicales.

\footnotetext{
* Este artículo es fruto de un estudio previo que culminó en la investigación anterior, en la que se aborda en profundidad el derecho de transformación de la obra musical, dada la doble formación académica de la autora como licenciada en Derecho-Abogada-, además de licenciada y doctora en Musicología. .

a. Licenciada en Derecho, Abogada y Mediadora por la Universidad de Oviedo, España. Doctora en Historia y Ciencias de la Música, por la misma Universidad.

Master en Patrimonio Cultural. CEO en el Despacho Suárez y Trelles Abogados de Oviedo. Profesora Asociada del Dpto. de Derecho Privado y de la Empresa de la Universidad de Oviedo.
} 
La hipótesis de partida es la profusión de imprecisiones, la falta de elementos que delimiten con seguridad la variedad de conceptos atribuibles a las obras musicales originales que puedan ser objeto de obra derivada; así como, la procastinación del legislador a la hora de abordar este problema. Se ponen de manifiesto las lagunas existentes y la falta de estudios al respecto en los dos ámbitos, tanto dentro de los estudios musicológicos, como en el tratamiento de la doctrina y la jurisprudencia nacionales que son escasas, también en relación con el derecho comparado.

\section{PALABRAS CLAVE}

Obra musical; derecho de transformación; plagio; apropiación intelectual; obra derivada; arreglo musical.

\section{ABSTRACT}

The article aims to present an interdisciplinary vision of the problem of the right of transformation of the original musical work and its possible conceptualization as a derivative work. As a result of the scarce treatment on the matter in the consolidated Spanish Intellectual Property Law, conflicts often arise when the author of an original composition authorizes its incorporation into a new one, holding the right for his work fully maintain its integrity without suffering impairment or deformation once its exhibition or exploitation has been consented. Within the legal and musicological context, the purpose is to give a transversal approach and to establish objective criteria related to the musical field that, dumped in the mold of intellectual property legislation, manages to provide solutions to the doubts that arise regarding the current and intricate conjuncture of the delimitation in transformations of musical works.

The starting hypothesis is the profusion of inaccuracies, the lack of elements that delimit with certainty the variety of concepts that are attributable to the original musical works that may be the object of derived works; as well as the procrastination of the legislator when addressing this very relevant problem. The existing gaps and the lack of studies in both topics are highlighted, both within musicological studies and in the treatment of national doctrine and jurisprudence which are rather scarce, also in relation to comparative law.

\section{KEYWORD}

Musical work; right of transformation; plagiarism; intellectual appropriation; musical arrangement; derivative work.

\section{RESUMO}

O artigo visa dar uma visão interdisciplinar do problema do direito de transformar a obra musical original e sua possível conceituação como obra derivada. Devido ao escasso tratamento do assunto que é dado pelo Texto Consolidado da Lei de Propriedade Intelectual Espanhola, freqüentemente surgem conflitos quando o autor de uma composição original autoriza sua incorporação em uma nova, detendo o poder de ter sua obra mantida integralmente intacta sem sofrer danos ou deformação, uma vez que você consentiu com sua exibição ou exploração. No âmbito jurídico e musicológico, pretende-se dar uma abordagem transversal e estabelecer critérios objetivos relacionados com o campo musical que, imersos na legislação de propriedade intelectual, consigam dar resposta às dúvidas que surgiram quanto à atual e intrincada situação da a delimitação da transformação das obras musicais.

A hipótese de partida é a profusão de imprecisões, a falta de elementos que delimitem com segurança a variedade de conceitos atribuíveis a obras musicais originais que podem ser objeto de obras derivadas; bem como a procrastinação do legislador ao abordar este problema. Destacam-se as lacunas existentes e a escassez de estudos nesta matéria em ambas as áreas, tanto no âmbito dos estudos musicológicos, como no tratamento da doutrina e jurisprudência nacional, que são escassos, também em relação ao direito comparado.

\section{PALAVRAS-CHAVES}

Tabalho musical; direito de transformação; plágio; apropriação intelectual; trabalho derivado; arranjo musical.

\section{INTRODUCCIÓN}

Con este trabajo pretendemos examinar los entresijos del derecho de transformación en el 
ámbito de la obra musical. Tema escasamente tratado, en el que existe mucha confusión y escaso régimen legal, teniendo en cuenta que no se aborda por el legislador hasta la reforma de 1987. En el trabajo doctoral Problemática de la obra musical derivada: la transformación como derecho patrimonial del autor de la obra original (GarcíaTrellez, 2019) se tuvo ocasión de profundizar y acometer el complejo estudio de la figura de la transformación como derecho patrimonial y más desde la perspectiva de las composiciones musicales, puesto que a lo largo de la Historia de la Música se encuentra profusión de ejemplos que ilustran este contexto y que demandan una ordenación racional para poder juzgar la existencia de derivación y originalidad aportada.

Se piensa en las leyes actuales y en la originalidad de las obras musicales. Dado que las creaciones musicales de cualquier género o época, en principio, deben considerarse originales, es necesario asumir lo que se ha visto comprometido en lo referido al talento $\mathrm{y}$ al ingenio en su creatividad. Las composiciones musicales están inspiradas y condicionadas por múltiples elementos, tanto internos como externos: la época al contexto del compositor o la función de la obra.

Existe un problema entre la incentivación del art, el conocimiento y la difusión de la música y la protección de las creaciones musicales, por lo que es necesario encontrar un equilibrio. Los sistemas legales de casi todo el mundo no van más allá de los límites que recortan las posibilidades de dejar sin tipificar las apropiaciones, por ello se considera que la persecución de fenómenos como la piratería no deben estar reñidos con la divulgación y la expansión de la obra musical como arte, más al contrario, sin perder de vista la importancia que tiene la difusión de la cultura no debemos permitir en ningún caso, que sea posible conculcar el derecho de un autor a que se respete y reconozca su obra.

Como se verá el derecho de transformación se refiere a la facultad del autor de explotar su obra, autorizando las creaciones que se deriven de ella, como pueden ser, desde el plano de la obra musical, los arreglos musicales, las adaptaciones, las transcripciones, las versiones, las sincronizaciones, los covers, el remix, los ensamblajes musicales, el sampling o las ediciones críticas. Estas acciones dan lugar a obras derivadas: una obra diferente, consecuencia de las modificaciones introducidas en la expresión de una composición musical, posteriormente a la creación original, de la mano de otros autores.

Abordamos esta figura sutil e intrincada del derecho de transformación desde la doble perspectiva jurídica y musicológica, intentando delimitar hasta dónde la alteración de una obra musical determina la producción de transformación y poniendo el foco en el eje que vertebra la consideración de la transformación, es decir, los casos en los que el autor-compositor incorpora a una nueva creación elementos de piezas musicales primigenias, dando como resultado una obra nueva, deudora en su expresión de la que transforma pero que aporta suficiente originalidad como para que pueda ser calificada como una nueva obra original.

\section{LA TRANSFORMACIÓN COMO DERECHO PATRIMONIAL DEL AUTOR DE LA OBRA ORIGINAL. DIFERENCIAS CON EL DERECHO MORAL}

Como cuestión previa al abordaje del derecho de transformación, conviene, establecer sus límites sobre todo en relación con otras figuras que podrían inducir a cierta confusión. Es importante diferenciar el derecho de transformación de otros derechos recogidos en el Texto Refundido de la Ley de Propiedad Intelectual -en adelante TRLPIpor lo que se tendrá que distinguir del derecho de reproducción, (artículo 18 del TRLPI) ${ }^{1}$ así como de los derechos morales de modificación (artículo 17), tal como se fundamenta en el derecho francés, como derecho del autor a que su obra permanezca íntegra. Cuando se habla del derecho del autor a la facultad de transformación, refiriéndose hace referencia al derecho que tiene el autor de una obra preexistente, cuando autoriza la incorporación de su obra en otra nueva; por tanto, al hablar del derecho a la integridad de su obra, se trata del derecho que tiene éste a que su obra no sufra menoscabo alguno, ni deformación, habiendo sido autorizada su exhibición o explotación. En este caso, el autor que ostenta la paternidad sobre su obra, de suerte que ésta no sea desconocida, defiende la integridad de su creación, detenta el derecho de ser publicada o no, y también tiene el derecho de arrepentirse y retirarla del comercio (Pérez, 1949, p. 9).

1. “...la fijación de la obra en un medio que permita su comunicación y la obtención de copias de toda o parte de ella". 
En el TRLPI de 1996 se trata -por primera vezel tema con muy poca dedicación, a pesar de ser una cuestión eminentemente práctica y habida cuenta de que el derecho de transformación tiene fama entre buena parte de la doctrina, de ser una de las materias más difíciles y complejas dentro del contenido de la propiedad intelectual (Román 2003, p. 378; Rivero, 1997, p. 42), amén de la incertidumbre que se padece a la hora de su abordaje por el escaso tratamiento en el TRLPI a pesar de su enfoque desde distintas perspectivas. Este derecho supone que se respete tanto al autor como menestral de la obra, y a la propia obra, por lo que su finalidad deviene doble: por una parte el autor tiene derecho a que su pensamiento no sea modificado o desnaturalizado, y por otra, la sociedad reclama el derecho a recibir una obra intelectual en su auténtica expresión ${ }^{2}$.

\section{LA OBRA DERIVADA COMO OBJETO DEL DERECHO DE TRANSFORMACIÓN}

Como resultado del ius transformandi se produce una modificación en la forma de la creación dando a la luz una obra lo suficientemente original derivada de otra desemejante, siendo esta consideración el verdadero núcleo, el elemento consustancial del hecho de la transformación, es decir, lo que hace diferentes al hecho creativo de la mera reproducción (Mariscal, 2013, pp. 325-326). El elemento original puede ser incorporado de distintas formas, puede darse en grados desiguales, de manera que en ocasiones es compleja su distinción: no es lo mismo la adaptación de una novela a un ballet; que el tema Yerterday grabado por Sinatra en 1969 como cover de la canción homónima de The Beatles de 1965 o la famosa Sinfonía (1968) de Luciano Berio mezcla de Ravel, Schoenberg, Stravinsky y Mahler.

En todo caso, para no calificar a la obra como totalmente independiente es imprescindible que la nueva creación contenga una aportación lo suficientemente identitaria de la obra original, es decir, se reconoce la obra primigenia gracias a la identificación de asuntos. Los oyentes,

2. Al respecto, López Sánchez, C. (2008) reflexiona: “Con carácter general consideramos que un atentado es sustancial cuando es susceptible de transmitir un sentido diferente al que el autor buscaba en su obra. Es decir, este ataque sustancial ha de afectar al corpus mysticum de la obra. Por ello, destruir o quemar la copia de un libro no constituye un atentado a la integridad de la obra del escritor, mientras que editar dicha obra después de haber eliminado o modificado algunos pasajes sí supondría un atentado a su integridad" (p. 6). mayoritariamente, reconocen el tema de un concertó grosso del siglo XVIII en un arreglo musical moderno, por ejemplo.

No es del todo factible obtener una definición precisa de obra derivada. La Organización Mundial de Propiedad Intelectual (OMPI) en su Glosario de Derechos de autor y Derechos conexos define como obra derivada :"aquella que se conoce en la doctrina como una obra intelectual (literaria, artística o científica) que se origina a partir de otra u otras obras preexistentes, de las que se dice que la nueva obra deriva" (1980).

El artículo 11 del TRLPI regula las obras derivadas ${ }^{3}$ y de su lectura se infiere que no existe una taxonomía limitada de obras derivadas, habida cuenta que se incluye dentro de esta categoría: "cualquiera transformación de una obra, literaria, artística o científica ${ }^{4}$. (Garrido-Falla, 2013) considera que no se limitan a una tipología o a un género de obras, cualquier creación en la que concurran estas características tendrá cabida dentro del artículo 11: unos arreglos musicales, una secuela de una película, la segunda parte de una novela, la escultura que se crea a partir de una fotografía, la reorganización de una base de datos... entre otros muchos ejemplos (GarridoFalla, 2017, pp. 197 y ss.).

\subsection{Las obras colectivas y las obras en colaboración}

En una actividad creativa pueden intervenir más de una persona, entonces hablamos de una obra colectiva o una creación en colaboración. El artículo 7 del TRLPI hace referencia a las obras en colaboración como "el resultado unitario de la colaboración de varios autores", cuyos derechos ${ }^{5}$ "corresponden a todos ellos". La aportación puede consistir desde la elaboración de los comentarios

3. Artículo 11. Obras derivadas: Sin perjuicio de los derechos de autor sobre la obra original, también son objeto de propiedad intelectual:

1.. Las traducciones y adaptaciones.

2.. Las revisiones, actualizaciones y anotaciones.

3.․ Los compendios, resúmenes y extractos.

4. ${ }^{\circ}$ Los arreglos musicales.

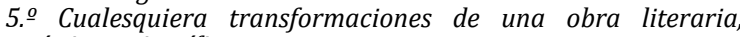
artística o científica.

4. En este sentido, también el Convenio de Berna, en su artículo 2.3, después de hacer mención expresa a las traducciones, adaptaciones y arreglos musicales, extiende la protección "a las demás transformaciones de una obra literaria o artística”.

5. Los derechos de explotación corresponden a todos los autores en la proporción que determinen. 
a preceptos legislativos, realizados cada uno por un autor distinto, a la composición conjunta de una obra musical o realización de una obra audiovisual o cinematográfica. Encontrándose todos los autores en una "relación de igualdad autoral" (Garrido-Falla, 2017, p. 355) al concurrir en la creación de la obra.

Es necesario apuntar que en la legislación española de propiedad intelectual cuando se habla de colaboración no quiere decir lo mismo que coautoría, ésta se da cuando varios autores contribuyen de forma indistinta a un resultado común, por ejemplo, cuando varios dibujantes ilustran conjuntamente un libro junto con otros autores que lo escriban, sin determinar en qué parte participó cada autor. La coautoría no deviene del pacto, ni tampoco de la colaboración, proviene del trabajo colectivo, sin que se pueda establecer la autoría individual según el artículo 5 del TRLPI ${ }^{6}$.

Las obras dramático-musicales entran de lleno en el supuesto clásico de colaboración en el ámbito musical. En estas composiciones musicales, lo normal es que un autor escriba el libreto, mientras otro crea la partitura. Como apunta De Román, cabe distinguir dos supuestos de obras en las que puede colaborar el compositor. En primer lugar, las que se crean íntegramente con contribuciones inseparables y en las que, normalmente, las aportaciones de cada uno de los colaboradores pertenecen al mismo género. $\mathrm{Y}$, en segundo, las formadas por contribuciones que se pueden explotar separadamente de la obra común y que, por lo general, pertenecen a distintos géneros ${ }^{7}$ (2003, p. 125). Ejemplo de las primeras pudiera ser la música improvisada por varios sujetos al mismo tiempo, o las obras musicales creadas por dos o más autores. Y del caso segundo, más numerosas que las primeras, serían las obras integradas por música y letra como los lieder, zarzuelas, óperas, canciones, etc.

Como es sabido, en este tipo de obras colaboran dos autores, uno escribe el texto y otro compone la parte musical. Pues bien, desde siempre esta circunstancia ha suscitado toda clase

6. Artículo 5. Autores y otros beneficiarios:

1. Se considera autor a la persona natural que crea alguna obra literaria, artística o científica.

7. De Román Pérez, R., Op., cit., p. 125. de dudas sobre el carácter de la indivisibilidad de estas creaciones.

Podemos detenernos en revisar lo que acontece en el panorama del derecho comparado, y cabe referir que en países como Alemania e Italia se habla de unidad cuando no exista posibilidad de explotación separada de las partes. En los artículos 5 y 6 de la LUG alemana de 1901, se recogen quizá los ejemplos más extremos al respecto, pues para este texto los autores del libreto y de la música de una obra dramático musical no merecían la consideración de coautores de una obra en común, sino que se considerarían autores de creaciones escindibles y perfectamente separables. En fecha 09.07.1909, el Tribunal Imperial de Alemania, en su Sala de lo civil, tuvo que pronunciarse en el caso Komische Oper v. Choudens (DdA,1910, pp138-142). La ópera Carmen del compositor Bizet (fallecido en 1875) con libreto de Meilhac (fallecido en 1897) y Halévy (fallecido en 1908), el cual fue traducido por Hopp en 1875, y aunque éste había fallecido en 1886, había caído en el dominio público en $1905^{8}$.

Cuando se iban a cumplir los 30 años de la muerte de Bizet, la cesionaria de los derechos sobre el libreto de "Carmen" en Alemania, la editorial Choudens, envió a los empresarios teatrales una carta recordándoles que todavía no había fallecido uno de los autores del libreto, por lo que toda representación de la ópera en Alemania tenía que obtener su autorización. Ante un conflicto en el que se enfrentó la editorial contra el teatro Komische, el Tribunal Imperial decidió que la ópera objeto del litigio no era una creación única indivisible, sino que estaba compuesta por

8. La facultad de explotación de una obra se prolonga durante 70 años después de la muerte del autor (art. 26 TRLPI); la que recae sobre el intérprete duran 50 años desde que tuvieron lugar o se publicaron en un soporte (art.112 TRLPI); la que recae sobre un fonograma dura 50 años desde la grabación (art.119 TRLPI); sobre un audiovisual duran también 50 años (art. 125 TRLPI); también duran 50 años sobre las emisiones o transmisiones (art. 127 TRLPI); sobre las fotografías duran 25 años (art. 128 TRLPI); lo mismo respecto de determinadas producciones editoriales (art.130 TRLPI). El derecho sui géneris sobre las bases de datos dura 15 años (art. 136 TRLPI). Transcurrido dicho plazo las obras de estos autores pasarán a dominio público (art. 41 TRLPI), para el caso de los autores, no habiendo un precepto como éste para los artistas, intérpretes o ejecutantes. Y no supone la desaparición de toda relación subjetiva entre el autor y la obra, ya que el párrafo segundo del artículo 41, obliga al respeto de los derechos morales de reconocimiento de la autoría (artículo 14,3) e integridad de la obra (artículo 14,4), como ya nos hemos referido anteriormente (Suárez, 2011, p. 123). 
dos obras totalmente independientes que por separado podrían correr su propia suerte desde el punto de vista del plazo legal de su protección. Por lo que, desde la sentencia, cualquiera en Alemania podría ejecutar la partitura de Carmen, e incluso junto a otro texto dramático distinto del original francés, como el traducido al alemán, ya que los derechos de reproducción de este continuaban bajo la propiedad del editor Choudens (Sánchez, 2005, p. 427).

Este criterio sigue manteniéndose en la legislación actual alemana, en la que solo cabe hablar de coautoría cuando la obra en común no pueda ser explotada separadamente. De manera que, en el caso de las obras dramático musicales, teniendo en cuenta que el texto o la música pueden ser explotados independientemente, serán los autores, el libretista y el compositor, quienes decidan esta circunstancia, por lo que aun constituyendo una unidad en el plano artístico ello no determina la consideración análoga en el plano jurídico. Sin embargo, la doctrina y jurisprudencia francesa defienden la total indivisibilidad, pues propugnan que en ningún caso se puedan tomar decisiones que afecten a la explotación de la obra en conjunto por cualquiera de los autores ${ }^{9}$.

Cuando hablamos del criterio aplicable en España para las obras en colaboración, que se regula en nuestro TRLPI en los artículos 7 y siguientes, debemos apuntar que ha prevalecido convencionalmente la indivisibilidad, aunque las contribuciones de cada autor sean perfectamente distinguibles. El legislador en este caso precisa que es necesario que todos los coautores den su consentimiento para la explotación de una obra en colaboración ${ }^{10}$

9. Tal es el caso de la sentencia de 06.07.1927, Lemoine \&Cie. C Consorts Donizetti, que estableció que las óperas de Donizetti, a pesar de haber fallecido éste en 1848, no se encontraban todavía en el dominio público, habida cuenta de que, dada la indivisibilidad que se producía en este tipo de obras en colaboración, el dies a quo respecto del cual computar el plazo legal de protección era la fecha de fallecimiento del último de los coautores (en el caso, uno de los libretistas muerto varias décadas después del maestro Donizetti). Por lo mismo, años atrás los herederos del compositor de la ópera La fille du regiment, lograron hacer valer la vigencia de sus derechos frente a un empresario teatral que los había desconocido. Al respecto vid. jurisprudencia sobre la indivisibilidad de la obra dramáticomusical en Francia, Ibid., p 429.

10. Textualmente el artículo. 7.2., dice: "Para divulgary modificar la obra se requiere el consentimiento de todos los coautores. En defecto de acuerdo el juez resolverá. Una vez divulgada la obra, ningún coautor puede rehusar injustificadamente su consentimiento para su explotación en la forma en que se
Tal y como se prevé en el mencionado artículo (apartado 2), y habida cuenta de que los coautores de obras intelectuales no pueden pedir "la división de la cosa común", como ocurre en la comunidad de bienes, en caso de desacuerdo el juzgador debe resolver lo procedente, como lo reconoce, entre otros, Carrasco (2007, p. 138-139).

No podemos dejar de mencionar el caso de las composiciones musicales como los lieder o las zarzuelas en las que colaboran dos o más autores al componer la música y la letra. Existe conocida jurisprudencia sobre zarzuelas que se explotaron sin el permiso de alguno de sus autores colaboradores, como la sentencia del Tribunal Supremo, de 4 de abril de 1936 (p. 4763) sobre La verbena de La Paloma (1894) y la Sentencia de 25 de octubre de 1941, sobre la revista La Gran Vía (1886) ${ }^{11}$. En la primera, Tomás Bretón el compositor de la obra, dispuso de ésta para ceder los derechos sobre la misma a una compañía discográfica, que reprodujo la obra y la distribuyó mediante fonogramas sin contar con la aprobación del libretista Ricardo de la Vega. La heredera de éste último demanda a la discográfica y el Supremo, aunque el tribunal de primera instancia había absuelto al demandado en casación, le da la razón a la recurrente.

En el caso de La Gran Vía, la Sentencia del Tribunal Supremo condena a los compositores de ésta habiendo demandado la SGAE (Sociedad General de Autores y Editores) como mandataria de los libretistas, por haber vendido ejemplares de dicha obra sin su consentimiento, es decir, solo con la autorización de los maestros Chueca y Valverde (Sánchez, pp. 371-372).

En lo que se refiere a las obras colectivas, por el contrario, para que se den los requisitos necesarios para su existencia, según lo que dispone el artículo 8 del TRLPI, tiene que haber una creación dada por la iniciativa y la coordinación de una persona natural o jurídica ${ }^{12}$ que la edita y divulga bajo su nombre, constituida por la aportación de distintos autores cuya cooperación personal queda subsumida en una única obra.

divulgó".

11, RJA, marg. no 1092.

12. Bataller Ruiz, E. (2002) dice: "Éste es un dato muy importante porque suele interpretarse el ejercicio de tales tareas como presupuesto de atribución de autoría, y por tanto de quiebra del sistema de atribución de derechos morales únicamente a las personas físicas" (p. 126). 
Según este precepto, "salvo pacto en contrario, los derechos sobre la obra colectiva corresponderán a la persona que la edite y divulgue bajo su nombre" 13. Sin embargo, Carbajo (1989) alude a este precepto en el sentido de resultar sorprendente que los derechos sobre estas obras colectivas correspondan, como decimos, a la persona que la edita y divulga -puede ser una persona jurídica-, produciendo una situación extraña al reconocer facultades creativas a quien no las ostenta, en contravención la más pura lógica (p. 3046).

La diferencia en este caso, radica en el papel que juega el coordinador de la creación, como único titular de los derechos sobre el resultado de la obra en colaboración ${ }^{14}$. En la obra colectiva el coordinador es quien dirige el trabajo de los autores, proporcionando las instrucciones necesarias; no como en la compuesta, en la que ningún autor dirige al resto, actuando todos con independencia, al respecto, Rodríguez y Bondía (2007), manifiestan:

En la obra compuesta, a pesar de incorporar en una obra nueva, múltiples obras preexistentes, no existe coordinación de estos autores, ni las obras preexistentes han sido creadas ex profeso para la obra común. El autor que incorpora una variedad de aportaciones de distintos autores, aunque éstos hayan podido coordinar sus trabajos entre sí, es autor de una obra compuesta y no editor de una obra colectiva, si no ha encargado los trabajos a los autores incorporados (pp. 48-49)

Llegados a este punto, puede sostenerse que la desemejanza que se da en la obra derivada en relación con la obra en colaboración y con la obra colectiva, se deriva del hecho de que en éstas, la creación intelectual de un conjunto de autores concurre para la creación de la misma obra, mientras que lo que regula el derecho de transformación, no es la concentración creativa sobre un mismo objeto, sino la actividad de un sujeto que crea una obra a partir de otra preexistente y autónoma.

13. El artículo 8 del TRPLI, se encuentra relacionado con los artículos 5.2, 28, 97.2 y 111 del mismo cuerpo legal.

14. Bataller Ruiz, E. (2002) dice: "Éste es un dato muy importante porque suele interpretarse el ejercicio de tales tareas como presupuesto de atribución de autoría, y por tanto de quiebra del sistema de atribución de derechos morales únicamente a las personas físicas" (p. 126)
Por consiguiente, un compositor que aporta una creación musical suya a una obra participada por las aportaciones de otros sujetos, se entiende que será una obra en colaboración cuando ésta se haya compuesto con la igual contribución de todos (no en un sentido estrictamente material, a tenor del contenido del artículo 7.4 del TRLPI); pero será una obra colectiva, si este compositor u otro colaborador ha tenido la condición de coordinador o realizador de aquélla. De facto será más normal que haya ocasiones en las que realice contribuciones a las obras colectivas (a una enciclopedia musical, por ejemplo), que aquéllas en las que coordine una de éstas (puede seleccionar y ordenar una serie de piezas que se han encargado a otros músicos sobre un determinado tema, editándose después en un disco compacto) (Román, p. 140).

\subsection{Criterios divergentes en la equiparación de obras compuestas y obras derivadas}

Se habla de obra compuesta en el caso de que para su creación se haya tomado la obra preexistente de otros que no participan en el proceso creativo. Este tipo de obras es regulado por vez primera en nuestro Derecho en la Ley de 1987 y consiste en la reelaboración o recomposición de una obra anterior creada por una persona distinta a quien lleva a cabo su transformación. En este sentido, la actividad realizada por el autor de la obra compuesta consiste en la incorporación de la obra preexistente a la obra que él crea.

Hay autores que identifican la obra compuesta con la obra derivada, otorgándoles un parentesco que otros niegan, con evidente división de opiniones al respecto. Mientras autores como Baylos (1978) y Bercovitz piensan que ambas se corresponden con una misma realidad, el primero; y que la obra compuesta debería considerarse como un caso de obra derivada, el segundo; aunque éste hace una clara diferenciación, puesto que apunta que el autor de la obra derivada es distinto de la obra originaria en la obra compuesta, mientras que la obra derivada no está sometida a semejante exigencia (1989, p. 567). Baylos opina que, en este caso "a cada uno de los autores de las obras conjuntamente publicadas, pero que constituyen "creación autónoma», le corresponderá la propiedad intelectual sobre su propia creación y, en cambio, carecerá de derecho alguno sobre las obras de los demás" (p. 568) ${ }^{15}$.

15. Baylos Corroza, refiriéndose a la antigua redacción 
Bercovitz habla, en este sentido, de una atención o esfuerzo inútil, por el escaso significado y lo aleatorio de su resultado (p. 189). En cambio, Galacho considera que la distinción es verdaderamente útil en lo que se refiere a la cesión del derecho de transformación; de manera que, si existe esta cesión, se está permitiendo la modificación de la forma de la obra en las variantes posibles sin que pueda ser tomada íntegramente en su estado original para crear una diferente; $y$, en cambio, en la obra compuesta estaríamos ante una obra derivada porque incorpora una preexistente, pero sin transformarla, lo que puede solucionar los conflictos que surgen a la hora de hablar del derecho de transformación (2014, pp. 76-77).

También existe la opinión de que la transformación es siempre una obra compuesta en tanto incorpora elementos de una obra preexistente sin la participación del autor de esta última. En este sentido se expresa Ayllón (2014, p. 144) citando a Lipszyc (1989, p. 112) y a Rivero (1997, p. 429), que mantienen la opinión de que es así en base al artículo 9 del TRLPI ${ }^{16}$.

Parte de la doctrina española y de la doctrina francesa entienden que la obra compuesta es una categoría general dentro de la que queda subsumida la obra derivada, en contraposición a la opinión que sostiene que la obra compuesta es un supuesto específico de obra derivada; por lo que toda obra compuesta será una obra derivada, pero no al contrario. No obstante, la cuestión es meramente doctrinal y no tiene gran recorrido, ya que en todo caso, el régimen de explotación de estas obras es el mismo (Mariscal, p. 355).

\section{3. ¿Es plagio o es obra derivada?}

Existe hoy una auténtica fiebre no solo en el mundo del arte, sino también en el académico en donde el plagio se encuentra presente en todos los debates. La sospecha se cierne especialmente en el mundo de la literatura en donde resulta altamente factible el libre acceso a multitud de conocimientos gracias a los procesadores de

del artículo 9.2 de la Ley, a cuyo tenor "se considera obra independiente la que constituya creación autónoma, aunque se publique conjuntamente con otras".

16. Obra compuesta e independiente: Se considerará obra compuesta la obra nueva que incorpore una obra preexistente sin la colaboración del autor de esta última, sin perjuicio de los derechos que a éste correspondan y de su necesaria autorización. textos y a las nuevas herramientas informáticas (Maurel-Indart, 2014).

En cuanto al término "plagio" nuestro TRLPI no lo menciona, solo en los artículos 138 y ss. se hace referencia a "infracción de derechos" y "actividad ilícita" y un sector de la doctrina ha dado en llamar a la copia sin autorización de su autor "usurpación". El Código penal sí lo contempla en su artículo 27, cuando establece:

Será castigado [...] quien, con ánimo de lucro y en perjuicio de tercero, reproduzca, plagie, distribuya o comunique públicamente, en todo o en parte, una obra literaria, artística o científica, o su transformación, interpretación o ejecución artística fijada en cualquier tipo de soporte o comunicada a través de cualquier medio, sin la autorización de los titulares de los correspondientes derechos de propiedad intelectual o de sus cesionarios.

Uno de los motivos por los que en nuestra opinión la ley es deficitaria en lo que a la propiedad intelectual en el ámbito musical se refiere, es entre otros, el hecho flagrante de que el plagio sea una de las figuras más utilizadas en lo que a reclamación de derechos de autor se refiere (Castán, 2009, p. 46), por lo que sorprende su falta de delimitación habida cuenta de la unanimidad existente a la hora de conceptuar el plagio como un triple atentado: de un lado, se conculca el derecho moral del autor; de otro, se atenta contra su derecho patrimonial (reproducción y transformación); y, por último, se infringe igualmente el interés público, en tanto que la obra plagiada, por no ser original, constituye un fraude para el consumidor (Ayllón, p. 303).

Según Galacho, la diferencia entre el plagio y la obra derivada se encuentra fundamentalmente en las modificaciones o en la cuota de contribución que el segundo creador inserte en su nueva creación, de forma que tenga la originalidad requerida para mover la balanza en un sentido o en otro (p. 80). Igualmente, considera que ambos supuestos tienen en común el respeto por la esencia y el espíritu de la obra original de manera identificable en la nueva obra. Se puede producir un plagio camuflado que se debe diferenciar de la obra derivada en el elemento sustancial como es la creatividad y originalidad del segundo autor. Es una empresa difícil, pero no debemos perder de vista las coordenadas que la conforman: en 
primer lugar, es necesario examinar en la obra presumiblemente derivada la asignación de originalidad que factura esa creación; para las obras derivadas esta exigencia de originalidad es relativamente menor que para las obras de nueva creación, por lo que la frontera pasa a ser muy sutil entre la obra plagiada y la derivada; $y$, el plagio que no suponga una copia literal (un "corta" y "pega") de la obra primigenia, quedará conceptuado como obra derivada cuyo autor no recabó el preceptivo consentimiento del autor original para transformar su obra.

Por lo tanto, si la obra plagiada posee un mínimo grado de originalidad y creatividad podría considerarse obra derivada, con los consiguientes derechos de autor que la ley concede (p. 473).

A mayor abundamiento y en aras de arrojar luz sobre un asunto con una diferenciación tan difusa, puede verse la sentencia de la Corte de Apelación de Milán de 12 de octubre de 1999 (p. 83) en el pleito que enfrentó al cantante $\mathrm{Al}$ Bano como demandante de plagio contra Michael Jackson, donde se confirma la resolución de primera instancia desestimando la pretensión del demandante, fundándose el juzgador en las numerosas composiciones preexistentes semejantes a la pieza de Al Bano, por lo que implicaba una falta de originalidad en su trabajo, que pretendía como obra originaria respecto a la canción, supuestamente copiada por el demandado Michael Jackson, concretamente unos pasajes de su canción Wil You (p. 474) ${ }^{17}$.

Baylos (1988) señala:

En el plagio existe siempre un enfrentamiento entre dos obras -la original plagiada y la plagiaria que es copia o reproducción parcial de la original-y el plagiario, que somete la obra original a un hábil proceso de deformación, introduciendo en ella modificaciones, cambiando aspectos formales, sustituyendo unos rasgos por otros equivalentes 0 semejantes, consiguiendo con ello hacer pasar como propios, bajo una presentación formal distinta de los valores intelectuales de la obra ajena, y tratando además, de que el autor de la obra plagiada no se percate del engaño ( $p$. 49).

17. Paradójicamente el demandante se puede convertir en plagiario.
En lo que se refiere al ámbito de la música popular en donde se centran la mayoría de los conflictos por plagio, nos encontramos con la dificultad de determinar a priori la verdadera originalidad de las composiciones por lo intrincado que resulta hallar composiciones donde paladinamente no se puedan encontrar parecidos o clonaciones de obras anteriores. Los compositores por lo general, suelen tomar el camino que ofrece menor resistencia y así, en las piezas para piano o para guitarra la tonalidad de Sol Mayor es de gran popularidad a la hora de componer, seguida de Do Mayor y Re Mayor 18. Ocurre lo mismo con la utilización de las progresiones armónicas, por ejemplo: algunas progresiones de acordes están fuertemente asociadas con una era específica, denominándose en ocasiones la "progresión de los años 50", acordes que pretenden evocar nostalgia o tristeza, alegría y júbilo juegan con las emociones del oyente. Esta utilización de forma sistemática en las composiciones de música popular hacen que la originalidad sea bastante difícil de hallar, de manera que surjan conflictos a la hora de determinar los parecidos con obras anteriores, siendo una empresa dificultosa por la repetición de esquemas compositivos en las composiciones de estas obras ${ }^{19}$.

Hoy no tendría sentido dejar de proteger obras de esta categoría y con coherencia no deberían ser tildadas de plagiarias, aunque no cuenten con la suficiente originalidad. No obstante y como señala Sánchez (p. 283), inicialmente se tenía muy en cuenta el número de compases que coincidían con la obra supuestamente plagiada, llegándose a establecer como "noción de semejanza sustancial"

18. En un estudio realizado por la plataforma Spotify (2015) Diego Arias, afirma: "Así que es probable que Sol Mayor sea la tonalidad más popular en el catálogo de Spotify porque también los instrumentos usados en la música contemporánea occidental pueden estar sesgados a ciertas tonalidades. A un pianista le resultará más cómodo interpretar tonalidades compuestas en su mayoría por las teclas blancas del instrumento como Do Mayor, Sol Mayor, o Fa Mayor.

Así mismo para un guitarrista hay ciertos acordes que son naturalmente fáciles de tocar dada la afinación estándar de las cuerdas. No en vano los primeros acordes que se aprenden en la guitarra son Mi Mayor, Sol Mayor, La Mayor, y Re Mayor."

19. En este sentido la sentencia de la CA Aix- en-Provence, del 3 de junio de 1957, “... en ella la Corte de Apelación concluye que las similitudes entre las dos obras en conflicto se ceñían a un pasaje de nueve notas que se utilizan de forma absolutamente habitual entre las obras del momento y cuya simplicidad conllevaba la imposibilidad de protección por los derechos de autor." (Galacho, p. 476). 
una combinación con el criterio cuantitativo, considerando determinante -relata refero- la llamada "regla de los seis compases", según la cual, por debajo de este número de coincidencia no existía plagio. Esta idea fue adoptada por muchos países, entre ellos España, y sigue aún vigente entre compositores, arreglistas e instrumentistas españoles, que todavía consideran que cambiando un compás de cada siete se actúa legalmente. Desde nuestro punto de vista este es un criterio erróneo y así queda recogido en la Sentencia de la Corte del Distrito Sur de Nueva York, de 9 de enero de $1980^{20}$.

Por lo expuesto, consideramos que cuando estamos ante una composición que ostenta una semejanza con otras anteriores con un mínimo de originalidad deberemos considerarla como obra derivada y nunca como plagio. Existiendo conflicto y llevado a los tribunales significaría que el plagio no es fácil de apreciar por lo que será más propio de calificar como actividad transformativa.

Lege ferenda, ante el hecho del plagio, nuestra opinión no puede ser más cercana a la de la mayoría de la doctrina que demanda a la Ley una respuesta, por lo que ha de determinarse el supuesto hecho concreto que supone el plagio para subsumirlo en alguno de los contemplados por la Ley, y admitirlo como una modalidad especial de infracción (Baylos, p. 57).

\section{EL ARREGLO MUSICAL COMO OBRA DERIVADA}

Estamos ante una figura de suma importancia para el mundo de la música, dado que es muy frecuente que las piezas musicales que escuchamos raramente procedan de la partitura original. Normalmente, hasta el momento en que el público escucha la composición, es habitual -especialmente en el mundo del pop- que ésta haya pasado por sucesivas transformaciones a manos de arreglistas profesionales.

En nuestro ordenamiento los arreglos musicales ${ }^{21}$ aparecen regulados específicamente, como ya se ha dicho, en el artículo 11. 4으.

20. Galacho hace referencia al fallo que estima la demanda por la copia de cuatro notas y dos palabras porque supone "el corazón de la composición" (p. 315).

21. El término "arreglo musical" aparece en el artículo 2.3 de la Convención de Berna de 9 de septiembre de 1886. del TRLPI, cosa que no ocurre así en otras legislaciones de nuestro entorno, como en la ley italiana y la ley alemana. Pero en ningún caso se encuentra una definición, lo cual nos lleva a intentar dar un significado, siquiera por señalar alguna de las características que hacen que sea incluida dentro del catálogo de obras derivadas. ¿Cómo define arreglo musical la bibliografía musical de referencia? en el Diccionario Harvard se designa con el término de arreglo musical a la adaptación de una composición para un medio diferente de aquél para el que fue compuesto originalmente, con la intención de conservar la sustancia musical sin cambios (Randel, 1084, $\mathrm{p}$ 84). De suerte que la sustancia musical se mantiene; o la elaboración -o simplificación- de una pieza, al margen de que se la someta o no a un cambio de medio (Boyd, 2001, p. 40). Es decir, el arreglo implica la posibilidad de intervención en dos variables sobre una pieza de partida: el medio de la pieza -generalmente referido al medio tímbrico para el que está pensado- o la propia materia musical, reelaborándola -muchas veces a favor de una simplificación de esta- , pero manteniendo la materia musical de la pieza de partida.

El Diccionario Oxford de la Música define arreglo como:

transcripción de una obra para un medio distinto de aquel para el cual fue compuesta originalmente la música; por ejemplo, una canción adaptada para piano o una obertura orquestal adaptada para órgano. Tal proceso, realizado con seriedad, implica mucho más que una simple transcripción musical en partitura, pues muchos pasajes funcionales para un medio pueden no serlo para otro. Por lo tanto, el arreglista debe imaginar lo que el propio compositor habría escrito si el nuevo medio hubiese sido el original (Lattan, 2008, p. 115).

Es decir, tanto en las referencias jurídicas como en las obras musicológicas, para definir el término arreglo se recurre a otros vocablos como reorquestación, instrumentación, transcripción o adaptación.

En la doctrina francesa, Desbois (1978) da una definición desde el término de adaptación como la anterior, y como transformación realizada 
desde el plano expresivo ${ }^{22}$, definición bastante estrecha que parece tener en consideración solo los arreglos instrumentales, tratando a éstos como "traducciones musicales", según opina cierto sector de la doctrina (Sánchez, p. 363) quien insiste en que la sola utilización del término "arreglo" implica ya una intervención sobre algo, por eso se atreve a articular una definición, en sus palabras -siquiera provisional-, según la cual, "la noción de arreglo musical debe entenderse referida a aquellas obras musicales derivadas en las que las transformaciones introducidas por el autor de las mismas a partir de una obra preexistente se proyectan exclusivamente sobre el plano expresivo, pudiendo afectar a cualesquiera aspectos de forma".

Esta afirmación está cargada de indefinición. Por una parte, "plano expresivo" no quiere decir nada técnicamente concreto, y nos llevaría a adentrarnos en el complejo problema del significado de la música que no es unívoco nunca $\mathrm{y}$ pocas veces es inefable. Podemos suponer -no sin temor a equivocarnos- que con la expresión "plano expresivo" hace referencia a la materialización sonora de la obra, a la acción de hacerla sonar, de interpretarla. En cuanto a la siguiente idea que le atribuye al arreglo, tiene que ver con la denominación "aspectos de forma". Aquí nos encontramos un nuevo problema de fondo, ya que los "aspectos de forma" para músicos y musicólogos tienen que ver con la estructura lingüística de la obra, no con las formas del signo frente a su fondo, que es como suponemos lo interpreta en esta definición el autor. Esto es, el autor podría querer decir que el arreglo se refiere a la parte de interpretación de la obra, y afectaría sólo a la parte formal del signo, no al fondo, al significado; a la sustancia significativa de la música como tal.

No debemos olvidar la consideración que hace la OMPI relacionando el arreglo con los términos reorquestación y transposición -o

22. Dice textualmente: "Se trata de la adaptación de una obra, escrita para un instrumento, a otro, o de la reducción de una sinfonía, para que pueda ser utilizada por uno o varios instrumentos tan sólo. El carácter derivado -de la obra- no ofrece duda alguna, pues el arreglista no incorpora melodía original alguna ni se permite, siquiera, variación alguna. Ello no quiere decir, sin embargo, que el arreglista no cree, en la estela de su predecesor, dado que tiene la oportunidad de manifestar su personalidad esforzándose en encerrar, en un marco restringido, los temas distribuidos entre una pluralidad de instrumentos" (pp. 143-144). transporte-. Reorquestación, transposición, instrumentación..., nuevos términos que vienen a sumarse a la indefinición de partida, generando nuevas dudas sobre el concepto de arreglo.

En cuanto a las obras derivadas, e incluso tratándose de obras independientes, la ley no establece un baremo que mida el grado de originalidad de los arreglos, que determine un criterio de protección o no de una partitura arreglada, por lo que los criterios a seguir vienen determinados por las líneas maestras que trazan los fallos judiciales, y a este respecto -como en muchos dentro de la problemática de los derechos de autor- tenemos que estar atentos a las resoluciones de los tribunales de fuera de nuestro territorio.

Por lo general, en materia de arreglos musicales parece que hay que alejarse de la opinión de los legos y recurrir a los análisis periciales, como en la actualidad está ocurriendo en la práctica jurídica española y de nuestro entorno para el caso del plagio musical; pero de todas formas, del estudio de la casuística más relevante se infiere que los tribunales no han dejado de combinar el test basado en el dictamen de peritos con el test del oyente medio ${ }^{23}$.

\subsection{Otras actividades al margen al arreglo musical como obra derivada:}

\subsubsection{La sincronización}

El Glosario de la OMPI en el concepto 246, define la sincronización como:

La adición de palabras habladas u otros efectos sonoros a una fijación audiovisual de manera que sean exactamente simultáneos como los correspondientes movimientos bucales y demás ademanes que aparecen. Un tipo especial de sincronización es el que consiste en dotar a una obra audiovisual de diálogos traducidos, pronunciados por personas distintas de los actores de la obra. Generalmente se entiende que el derecho de

23. Se entiende la importancia de su utilización en los casos de plagio musical, aludiendo a la característica distintiva del discernimiento que cualquier persona puede captar "de oído". En una sentencia de 2004 la Audiencia Provincial de Barcelona se reconoció protección a una composición de música electrónica de techno-dance titulada "Guitar Spell". El tribunal en este caso analizó la originalidad derivada de la transformación de una obra de techno-dance a través del procedimiento "test del oyente medio". SAP de Barcelona (rec. 153/2002), de 5-3-2004. 
adaptación cinematográfica comprende el derecho de sincronizar las obras adaptadas.

Por otra parte Chion (1993) se refiere a la sincronización como "encuentro síncrono entre un instante sonoro y un instante visual", llamando al justo momento de encuentro "punto de sincronización" (p. 61).

La sincronización es muy utilizada en las producciones audiovisuales: cortos, películas, anuncios comerciales, vídeos corporativos,

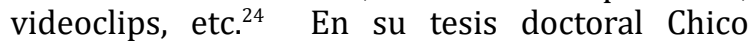
(2018), conviene en la necesidad de estudiar los tipos de sincronizaciones que se pueden dar a la hora de recoger el amplio espectro que existe de posibilidades entre la división y unificación, causalidad e intencionalidad $y$ exactitud $e$ imprecisión de la aleatoriedad sincrónica: "obligan al espectador a crear la continuidad de la secuencia a través de la asimilación del conjunto de la escena, de conectar las imágenes de nuestra memoria unida al sonido con la imagen del filme... "(pp. 101-102).

Existen opiniones que destacan que la obra musical adquiere una nueva proyección y significado cuando se plasma junto a imágenes, sonidos, otras obras o prestaciones de propiedad intelectual ${ }^{25} \mathrm{y}$, es aquí, donde está el núcleo del asunto que nos interesa: ¿podemos hablar de una obra nueva?, ¿estamos ante una obra derivada? En nuestra opinión, si se trata de adaptar el tema musical a un medio para el que no fue creado, debería recabarse el consentimiento del creador, podríamos estar hablando de transformación; también se trataría de obra compuesta si tenemos en cuenta la combinación de música e imágenes, por autor distinto del de la obra originaria ${ }^{26}$.

Por regla general en nuestro país suele ser la Sociedad General de Autores y Editores (SGAE) quien, realizando una labor de intermediación, obtiene la autorización del autor de la pieza musical para utilizarla, en un anuncio o en una película. Sin olvidar que siempre deberá ser

24. En la actualidad a través de software como ProTools.

25. Al respecto, en palabras de Nieto (1996): "la asociación de la música e imagen está basada en un cierto grado de articulación entre ellas. El grado de esta articulación es muy variable y dependerá no solo de las necesidades de la película, de su género y de su estilo, sino también de la voluntad del propio compositor al abordar su trabajo" (p. 134).

26. Recordemos lo expuesto supra. respetado el derecho moral del autor que ante un caso de sincronización de su partitura musical en un contexto nuevo, cobrando otro significado o expresión divergente a la insuflada por el autor primigenio, no está dispuesto por los motivos que sean a asumir. Siempre quedará reservado el derecho a la integridad de la obra, como derecho inalienable e irrenunciable.

\subsubsection{La transposición}

No existe en nuestra legislación esta acepción y el término se encuentra poco definido por los autores, siendo utilizado indistintamente en sede de obra derivada. Encontramos una definición en el Diccionario Akal/Grove de la Música, referida a la escritura o ejecución de una partitura “...a una altura distinta a la que fue originalmente concebida, bien subiéndola o bien bajándola el mismo intervalo" (2000, p. 955).

Es utilizada en el caso de obras que se interpretan por instrumentos distintos para los que se escribieron, por ejemplo el de la Suites para violonchelo de Bach, cuando se interpretan en la viola, deben ser transportadas una octava más agudas -por las características idiomáticas del nuevo instrumento que las va a ejecutar-. En muchos de estos casos se utiliza el término versión para referirse a lo que es una verdadera transposición, de ahí la confusión que se padece en lo que se refiere a la utilización indistinta de los términos.

Habida cuenta de que lo que no es objeto de discusión es el carácter meramente técnico de su empleo ${ }^{27}$, consideramos que esta actividad es ajena al arreglo musical como obra derivada.

\subsubsection{La transcripción}

Nos encontramos nuevamente con un término polisémico dentro de un supuesto particular. Se puede considerar como la acción de cambiar la partitura de medio instrumental o sonoro, por ejemplo, cuando se transcribe una obra orquestal para piano, o transcribir para guitarra una obra para piano, como en el caso de la Suite Iberia para piano de Albéniz, cuando se quiere interpretar

27. Existen incluso programas informáticos como Sibelius, Finale, Musescore, Lilipond, Tuxguitar, etc, que ejecutan la transposición automáticamente. A pesar de ello, estos programas no son capaces, por ejemplo, de transportar de forma correcta la escritura de los instrumentos transpositores de una orquesta sinfónica, como clarinetes, corno inglés, trompas o trompetas, por ejemplo. 
a guitarra. También sería el caso de cambiar la notación gráfica de una pieza -convertir una partitura de cifra o tablatura en escritura en pentagrama-.

Como decíamos, al hablar de la transposición, en el caso de la transcripción, los autores no clarifican demasiado esta terminología de manera que ambos términos también aparecen relacionados en ocasiones a pesar de contar con un significado, semánticamente hablando, muy diferente.

En el contexto de las obras derivadas, una primera acepción para tener en cuenta es la de "plasmar la composición de forma gráfica en un lenguaje musical distinto del que venía expresado" (Román, p. 85). En cambio, consideramos, que Sánchez no comprende el término en toda su extensión por cuanto no atiende a la riqueza de acciones que implica la idea de la transcripción, reduciendo el acto al contexto de interpretación, más que al de la creación, pudiendo ser realizadas "sobre la marcha por los propios artistas a fin de facilitar su propia tarea de interpretación o ejecución". Esta afirmación es del todo incorrecta al no corresponder con ninguno de los conceptos técnicos de transcripción (p. 321).

Sí compartimos totalmente la afirmación de la profesora De Román, quien considera a la transcripción como obra derivada, calificando el término como "traducción" e "interpretación" paleográfica de una grafía musical de otra época o cambio de medio de una partitura, supuestos en los que el trabajo del musicólogo consiste en una labor filológica sobre el texto o los textos de la obra y una investigación contextual (p. 86).

Se hace necesario puntualizar que la partitura transcrita como obra resultante de la transcripción no se considera obra del musicólogo que realiza esta labor, por razones obvias no podrá ser explotada por éste. Será necesario que proteja la obra por medio de la normativa de propiedad intelectual como ocurre en el dominio público, junto con el proceso de reconstrucción, comentarios, fuentes, digitación ${ }^{28}$, etc., con el

28. Galacho Abolafio, citando a Fishman (2010, p. 110) subraya que "muchas nuevas ediciones de obras de dominio público contienen sugerencias sobre la digitación con que ha de ejecutarse la obra para teclado. La digitación consiste en asignar números (que corresponden a los dedos de la mano: 1 al dedo pulgar, 2 al dedo índice, 3 al corazón, 4 al anular y 5 al meñique) objeto de conseguir una aproximación lo más fiel posible a la partitura musical tal como fue creada por el compositor. Sin embargo, dicha protección no caerá sobre la obra en sí misma, sino en su edición y hasta después de 25 años de su publicación. He aquí la justificación de que muchas editoriales musicales sigan explotando las partituras de obras de dominio público como consecuencia de haber realizado un trabajo de investigación para editarlas, con aportaciones de tal calibre que el resultado se pueda considerar obra derivada.

3.2. Los "covers" y la relación con el original

Se conoce como versión o "cover" el resultado de grabar o interpretar la obra de otro compositor, cantante o grupo musical de otra época o estilo musical. Witmer y Marks (2001) afirman que "también puede aplicarse a una regrabación de una canción por parte de los intérpretes originales (generalmente usando seudónimo) para una compañía discográfica rival.

En el mundo anglosajón se utiliza el término "cover" para darle nombre a estas versiones en clara metonimia, recurriendo a la palabra que define la portada de un disco LP -cover- dado que en los años cincuenta y sesenta del siglo XX, una portada [cover] consistía en la regrabación de una canción, con el fin de hacerla llegar a la mayor cantidad de personas posible, incluso a diferentes consumidores, además de a aquellos que hubieran comprado la versión original.

Este procedimiento de adaptación y diferentes interpretaciones de un tema previo, es lo que Mosser denomina "canción base", refiriéndose a aquellas grabaciones que "debido a su status, popularidad u otras razones, son tomadas como paradigmáticas" (en López, 2018, p. 104) ${ }^{29}$, y sirven para comparar el resto de grabaciones. Es frecuente que el oyente posea en su memoria una interpretación distinta de la de otro sector de la población (variantes como la edad o la nacionalidad del oyente son importantes) López

a las notas escritas de la partitura, para que la interpretación de la obra resulte lo más cómoda posible. Estas no suponen una aportación de originalidad, sin embargo, las que van más allá, tratando de conjugar la comodidad de ejecución con el respeto al estilo de la obra de que trate, proponiendo varias digitaciones justificando del porqué de cada una de ellas, podrán dar lugar a una obra derivada protegible" (2014, p. 110).

29. refiriéndose a la obra original o primigenia según Mosser K. (2008). Cover songs»: Ambiguity, multivalence, polysemy, Popular Musicology Online, 2. 
Cano comenta este suceso al referirse a la canción Te recuerdo Amanda de Victor Jara, que fue una grabación de Joan Báez pero que, por ejemplo, para los argentinos la recordada es la de Mercedes Sosa.

Existen canciones que han gozado de tantas versiones que el original termina extraviándose, a la vez que se asocia con los nuevos intérpretes. Uno de los mejores ejemplos nos lo ofrece la canción My way, una de las obras que presenta más versiones de la historia contemporánea. Ha sido universalmente difundida en la versión inglesa, bajo la interpretación de Frank Sinatra, pero en realidad, es una canción original francesa, escrita dos años antes, en 1967, por Claude François y Gilles Thibaut con el título Comme d'habitude, que fue puesta en música por Claude François y Jacques Revaux. La versión en inglés solo mantiene la melodía original, ya que la letra fue reescrita por el cantante canadiense Paul Anka en 1969 y es totalmente diferente de la original en francés (Manrique, 2004).

Volvemos a hacer hincapié en la situación deficitaria en lo que a regulación se refiere relativo al derecho de transformación que en ocasiones se torna complejo por la escasa delimitación legislativa existente y por la propia identidad de esta figura. En el tema de las versiones se da el mismo problema, el vínculo entre la versión actualizada y la pieza de referencia: ¿estamos ante la misma canción, pero con diferente manifestación?, ¿es un caso de obra derivada que mantiene una clara independencia de la obra original o son dos obras distintas que se relacionan entre sí? Sin embargo, consideramos que la versión es una obra derivada porque con la misma existencia del original queda garantizada una identidad distinta.

\subsection{El sampling o reciclaje digital}

El muestreo o sampling como "práctica general de extracción de fragmentos de grabaciones previas de música, discursos y paisajes sonoros, para insertarlas en nuevas creaciones musicales" (López, 2012, pp. 273 y 287), se fundamenta en la circulación de la música como objeto: sonidos que, insertados en soportes, no actúan por ejecución, sino por reproducción. Cuando el sonido es almacenado digitalmente, consigue una calidad muy superior en relación con el grabado analógicamente ${ }^{30}$, los ruidos de fondo se eliminan y se evita la degradación que puede sufrir el soporte con el paso del tiempo.

Galacho, apunta que "lo mejor del sampling es su inestimable aportación a la literatura musical. Lo peor es el vandalismo y el robo que ello puede suponer" (p. 313). El autor demanda nuevas interpretaciones sobre los problemas relacionados con la infracción de los derechos de autor e incluso con la competencia desleal. A fin de cuentas, el "sampler" no deja de ser una muestra de sonido que se recoge en cualquier soporte para luego utilizarlo como si de un instrumento musical se tratase. Se han producido muchas soluciones para evitar las exitosas demandas por la utilización de los samplers. El empleo de los sintetizadores por los ingenieros de sonido para procesar éste con la ayuda de la información digitalizada de los samplers, camuflándolos para diluirlos en una nueva creación, consigue un resultado en apariencia fuera del uso de material protegido.

No obstante, los criterios y pronunciamientos judiciales en Estados Unidos (en España es muy escasa o casi nula la doctrina jurisprudencial al respecto) son tendentes al extremo, o bien se restringe mucho el uso por terceros no autorizados de las grabaciones de sonidos 0 , por el contrario, se considera uso legítimo la utilización de grabaciones cuando el resultado no es muy similar ${ }^{31}$.

30. En referencia a la digitalización del sonido, Boabide Fernández, C. (1996). describe esta acción: "Para digitalizar un sonido se toma un dato del mismo varias decenas de miles de veces por segundo. Puesto que el oído humano no es capaz de percibir frecuencias superiores a 20.000 ciclos por segundo, tal velocidad de digitalización es suficiente para tomarlo con toda la perfección necesaria" (p. 54).

31. El fallo de Sixth Circuit 2005, en Bridgeport Music, Inc v. Dimension Films, reforzó la tesis de que el muestreo de grabaciones de sonido constituye per se una infracción de derechos de autor. Después que el Tribunal de primera instancia determinara que el muestreo relevante es de minimis -expresión latina propia del lenguaje jurídico que se refiere a lo que no infringe la Ley, lo que no tiene la suficiente importancia para que la ley le preste atención. Proviene de las expresiones latinas de minimis non curat praetor y de minimis non curat lex- el Sexto Circuito no estuvo de acuerdo, al encontrar que cualquier muestra es una infracción de derechos de autor (subrayado nuestro). El Tribunal sostuvo específicamente que no se debe emprender una "investigación de minimis... cuando el demandado no ha negado que realizó una muestra digital de una grabación de sonido con derechos de autor". El muestreo no autorizado es objeto de infracción a falta de un hallazgo de uso justo. [46410 F.3d 792, 801-02 (6th Cir. 2005)]. El Noveno Circuito, en cambio, adoptó expresamente la doctrina del fair use (realización de copias sin pedir permiso) en 2016 para el 
Sin embargo se alzan voces ante el fenómeno del sampling, en cuanto debería tenerse en cuenta como una técnica puesta al servicio de la creatividad musical en la mayoría de las ocasiones, y no solo como una herramienta a disposición de piratas discográficos, que lo único que pretenden es potenciar métodos más fáciles que la mera creación musical.

De todas formas, es indudable que ante el fenómeno del sampling nos encontramos en sede de obra derivada; de cualquier manera que se emplee, ya sea como la reproducción textual de un fragmento o de una grabación, estaríamos ante una obra derivada por organización de contenidos - o como la grabación de una parte de una obra original para, tras su modificación y reciclaje, insertarla en la composición de nueva creación. Según opinión que compartimos totalmente, Millé (1994) considera, que incluso en el caso de que partiendo de una obra original analógica se introdujeran o eliminaran instrumentos, voces, efectos, alterando la melodía, la letra, el ritmo, etc., estaríamos hablando, de transformación de la obra musical analógica en obra digital derivada de la modificación sustancial de la anterior (p. 25).

\subsection{El "remix" o remezcla}

Aunque brevemente debemos detenernos en este procedimiento muy utilizado en la actualidad cuya procedencia parte de los años setenta, en la época de oro de la música disco. La pista original de la grabación de una canción con un considerable éxito, era intervenida para alargarla más tiempo de los tres minutos de rigor con el fin de prolongar el baile durante más tiempo. A esta versión bucle se le llamó remix musical.

Hoy en día, denominamos remezcla o "remix" a una grabación producida mediante secciones de pistas grabadas ya existentes que se combinan

muestreo de grabaciones y composiciones de sonido, divergiendo explícitamente del caso Bridgeport. El asunto, "VMG Salsoul vs. Ciccone", abordó si una muestra irreconocible en la revista Vogue de Madonna, constituía una infracción de la grabación sonora del trabajo anterior y la composición. La opinión caracterizó a Bridgeport como un caso atípico, señalando que más allá de él y su progenie, "no tenemos conocimiento de ningún caso que haya sostenido que la doctrina de minimis no se aplique en un caso de infracción de derechos de autor". Se aplicó por el Tribunal la similitud sustancial versus el estándar de minimis de forma consistente tanto para la grabación de sonido como para los derechos de autor de la composición. No se encontró en este caso ninguna infracción. [VMG Salsoul, LLC v. Ciccone, 824 F.3d 871, 884 (9th Cir. 2016)]. con nuevos patrones y nuevo material (López, p. 286).

Como ocurre con los arreglos musicales, una buena remezcla puede llegar a obtener mucho éxito -incluso más que la obra originaria-. Desde el mundo de la tradición compositiva esta actividad se mira con cierto recelo y tanto los creadores como sus obras son discutidos en algunos ámbitos musicales.

En cuanto al derecho de transformación debe quedar claro que si el remix aporta algún rasgo de originalidad en relación con la obra de la que parte, será considerada obra derivada; y si por el contrario, carece de este atributo será solo una obra inspirada o parecida, aunque con ciertas peculiaridades ${ }^{32}$.

\section{EL USO DE LAS NUEVAS TECNOLOGÍAS Y SU RELACIÓN CON LA OBRA DERIVADA. LA SENTENCIA DE LA AUDIENCIA PROVINCIAL DE MADRID DE 5 DE ABRIL DE 2010}

La consideración de la obra derivada en el ámbito de las nuevas tecnologías no es baladí, si bien la repercusión de una creación que pueda considerarse como tal no se encuentra en el medio a través del cual se obtuvo, sino en el resultado producido, si la obra se sigue identificando con la original esencialmente, no nos encontramos ante una composición independiente, pero si por el contrario, añade una importante dosis de creatividad entonces, estaremos hablando legalmente de una obra derivada.

En lo que se refiere a este método denominado "reproducción fragmentada" a propósito de las nuevas tecnologías, existen dos sentencias ${ }^{33}$ que ponen de relieve muy elocuentemente esta relación. Se trata de delimitar si a un ringtone se le puede otorgar la categoría de obra derivada. La sentencia recurrida se guía por esta valoración

32 Al respecto, importante es lo establecido en: SAP de la Audiencia Provincial de Madrid, (Sección 28) de 5 de abril de 2010. Donde en relación con la originalidad establece: "la nota de originalidad concurre cuando la forma elegida por el creador incorpora cierta especificidad tal que permite considerarla una realidad singular o diferente por la impresión que produce en el destinatario, lo que, por un lado, ha de llevar a distinguirla de las análogas o parecidas $y$, por otro, le atribuye cierta apariencia de peculiaridad".

33. SAP de Madrid de 5 de abril de 2010 [JUR 2010, 204952], y STS de 18 de diciembre de 2012 [JUR 2013, 23864] ya citada anteriormente, por la que se confirma la anterior. 
y señala que los arreglos requirieron "realizar una sinopsis armónica, melódica y estética" de las canciones "que determinaron una realidad acústica diferente de la obra originaria, aunque tratase de hacerse reconocible como ésta".

En lo que se refiere al valor de esta actividad llevada a cabo sirviéndose de las nuevas tecnologías, se debe tener en cuenta la creatividad aportada, que no consiste en una simple mecanización en la utilización del material originario, de manera que se considera por ambos tribunales que el resultado produce una obra derivada. Esto trae consigo la necesidad de un contrato de transformación para llevar a cabo estas actividades habida cuenta de la valoración efectuada por el perito judicial ${ }^{34}$, evaluación que prosperó totalmente a los efectos de la sentencia.

A este respecto, Galacho concluye que este hecho "conduce a que no se valore adecuadamente y de forma diferenciada del resultado final como obra derivada, el proceso creativo a través de las nuevas tecnologías [...] No podemos por menos que estar de acuerdo con el fallo de la sentencia, y considerar que en efecto, el resultado ha de ser considerado como obra derivada y que se ha ejercido el derecho de transformación de forma ilícita" (p. 360).

\section{BREVE ALUSIÓN A LOS DERECHOS EN RELACIÓN CON LAS EDICIONES CRÍTICAS MUSICALES}

Dentro del artículo 11 apartado $2^{\circ}$ del TRLPI, se encuentran las actualizaciones, revisiones $y$ anotaciones. Por lo que la edición crítica podría considerarse como obra derivada teniendo en cuenta su originalidad y aporte creativo vertidos sobre la obra originaria.

Las ediciones críticas permiten que el texto de la partitura sea interpretado, con el fin de facilitar la ejecución al intérprete. Cuentan, por tanto, con un corpus crítico en el que se recogen las alternativas, opciones expresivas, comentarios o el abordaje de una simplificación textual, haciendo referencia a aquello que no coincida con la notación original. Es cometido de los

34. Literalmente se recoge: los arreglos musicales requirieron "realizar una sinopsis armónica, melódica y estética" de las canciones "que determinaron una realidad acústica deferente de la obra originaria, aunque se tratase de hacerse reconocible como ésta". musicólogos poner a disposición de los intérpretes de un contexto histórico distinto y distante, una partitura lo más fiel posible a la voluntad del autor; interactuando con el compositor, tratando de interpretar lo más honestamente posible su voluntad creativa, ideal a veces imposible, puesto que resulta una labor verdaderamente no exenta de complejidad.

En cuanto a su alcance jurídico la cuestión no es pacífica entre la doctrina, sin embargo, prima la opinión de los autores que consideran estas obras no solo como obras derivadas, sino como verdaderas transformaciones, porque afectan a elementos expresivos de la obra musical, además de por su originalidad, aporte creativo añadido a la composición primigenia.

Sobre las ediciones críticas de obras caídas en dominio público, hay que puntualizar que, según sus características editoriales, pueden constituir por su tipografía, presentación, etc., objeto de un derecho afín al derecho de autor; nos referimos a otro derecho de propiedad intelectual contemplado en el artículo 129.2 del TRLPI $^{35}$. Por lo que será protegida al recoger las notas y comentarios con carácter personal y en consecuencia, las prerrogativas y cualidades del autor no deberían cuestionarse.

\section{CONCLUSIONES}

El estudio de la Ley nos ha puesto de relieve la existencia de un elenco importante de disposiciones que directa o indirectamente se relacionan con la trasformación de la obra, produciéndose un problema de delimitación de este derecho de explotación respecto al derecho de reproducción, entrando en juego en ocasiones el derecho moral a la integridad de la obra íntimamente ligado con el derecho que posee el autor a la modificación de su obra.

Consideramos que la distinción entre obra derivada y obra compuesta es muy importante,

35. El artículo 129 del TRLPI establece: "Obras inéditas en dominio público y obras no protegidas.1. [...]; 2. Del mismo modo, los editores de obras no protegidas por las disposiciones del Libro I de la presente Ley, gozarán del derecho exclusivo de autorizar la reproducción, distribución y comunicación pública de dichas ediciones siempre que puedan ser individualizadas por su composición tipográfica, presentación y demás características editoriales". para la profundización en lo referido a los "derechos afines" se recomienda seguir a De Román Pérez: Op., cit., pp. 507 yss. 
aunque no sea así como opina mayoritariamente la doctrina; si existe la cesión del derecho de transformación se está consintiendo en la modificación de la obra, es decir, se estará tomando íntegramente una obra original para crear una diferente derivada; y, en cambio, en la obra compuesta estaríamos ante una obra que lleva a cabo una incorporación material de la preexistente, pero sin transformarla.

Tratándose por parte del artículo 21 la transformación como un acto en sí mismo y no siendo igual la realización de la actividad transformadora que la obra derivada resultado de esa actividad, consecuentemente debemos considerar la diferencia existente entre la creación de la obra derivada y la explotación subsiguiente, producto de dos actos diferentes con las distintas autorizaciones consiguientes.
La pieza musical que contiene una semejanza a otras anteriores relativa a lo sustancial y ostentando un mínimo de originalidad (siendo objeto de propiedad intelectual), será considerada obra derivada y no obra plagiaria.

En lo referido a los arreglos musicales precariamente tratados, pues sólo merecen por parte de la ley un simple epígrafe en el artículo 11 , sin que se tenga claro hasta dónde alcanza la protección de esta figura. Siendo conscientes de que el arreglo musical está considerado como el paradigma del derecho de transformación se hace necesario que legislativamente sea contemplado de forma que se proporcione un baremo con el que determinar el amparo legal del arreglo y echándose en falta, para los casos de conflicto, soluciones jurisprudenciales -que son muy escasas- al respecto.

\section{BIBLIOGRAFÍA}

- Ayllón Santiago, H. (2014). El derecho de transformación de las obras del espíritu. Madrid: Editorial Reus.

- Bataller Ruiz, E. (2002). La obra colectiva. Valencia: Editorial Tirant lo Blanch.

- Baylos Corroza, H. (1978). Tratado de la Propiedad Industrial. Madrid: Editorial Civitas.

- Baylos Corroza, H. (1988). "Disquisición sobre el plagio". República de las Letras, Revista de la Asociación Colegial de Escritores. No. 20. (enero, 1988)

- Bercovitz Rodríguez-Cano, R. (1989). Comentarios a la Ley de Propiedad Intelectual. Madrid: Editorial Tecnos.

- Boabide Fernández, C. (1996). Las nuevas tecnologías o las creaciones intelectuales. Aspectos positivos en El derecho de propiedad intelectual y las nuevas tecnologías, Madrid: Ministerio de Cultura y Deporte.

- Boyd, M. (2001). Arrangement. New Grove Dictionary of Music and Musicians. Sadie, Stanley \& Tyrrell John (eds.). Londres: Editorial Macmillan.
- Carbajo González, J. (1989). "La nueva regulación española en materia de propiedad intelectual I" . Actualidad Civil, No. 3.

- Carrasco Perera, A. (2007). "Comentarios al artículo 7 TRLPI". En: Comentarios a la Ley de Propiedad Intelectual. Bercovitz Rodríguez-Cano (Coords.).Madrid Editorial Tecnos.

- Cascudo, T. (2010). "Introducción y notas". El arreglo como obra musical. Ciclo de miércoles. Madrid: Fundación Juan March.

- Castán Pérez-Gómez A. (2009). El plagio $y$ otros estudios de derechos de autor. Madrid: Editorial Reus.

- Chico López,J.M. (2018). La sincronización sonoro-visual: relaciones surgidas a partir de la práctica artística. Tesis Doctoral. Universidad de Granada. Disponible en http://hdl.handle.net/10481/51836.

- Chion, M. (1993). La audiovisión. Introducción a un análisis conjunto de la imagen y el sonido. Barcelona: Ediciones Paidós. 
- De Román Pérez, R. (2003). Obras musicales, compositores, intérpretes y nuevas tecnologías. Madrid: Editorial. Reus.

- De Román Pérez, R. (1996). “Problemática de las obras derivadas de propiedad intelectual. Jurisprudencia civil y penal". Estudios sobre el Ordenamiento jurídico español. Burgos: Universidad de Burgos.

- Desbois, H. (1978). Le Droit d'auteur en France. París: Editorial Dalloz.

- Diccionario Akal/Grove de la Música. (2000). Madrid: Editorial Akal.

- Fishman, S. (2010). The Public Domain: How to find \& use copyright-free writing, music, art \& more. Nueva York: Editorial Berkely.

- Galacho Abolafio, F. (2014). La obra derivada musical: entre el plagio y los derechos de autor. Pamplona: Editorial Aranzadi.

- García-Trelles Fernández, C. M. (2019). Problemática de la obra musical derivada: la transformación como derecho patrimonial del autor de la obra original. Tesis Doctoral. Universidad de Oviedo. Disponible en http://hdl.handle. net/10651/52830.

- Lathan, A. (2008). Oxford Diccionario Enciclopédico de la Música. México: Fondo de Cultura Económica.

- Lipszyc, D. (1989). "La protección de las obras literarias y la política cultural del libro" En: Memoria del IV Congreso Internacional sobre la protección de Intelectuales. Madrid: Organización Mundial de la Propiedad.

- López Cano, R. (2012). "Lo original es la versión: covers, versiones y originales en la música popular urbana". ArtCultura. Vol. 14. No. 24.

- López Cano, R. (2018). Música dispersa. Apropiación, influencias, robos, remix en la era de la escucha digital. Valencia:
Editorial MusiKeon Books.

- López Sánchez, C. (2008). La transformación de la obra intelectual. Madrid: Editorial. Dykinson.

- Manrique, D. A. (2004). "La sorprendente historia de My Way". El País, 7-042004. Disponible en: https:// elpais.com/diario/2004/04/07/ espectaculos/1081288802_850215.html

- Mariscal Garrido-Falla, P. (2013). Derecho de transformación de la obra derivada. Valencia: Editorial Tirant lo Blanch.

- Mariscal Garrido-Falla, P. (2017). "Comentarios al artículo 11". En: Comentarios a la Ley de Propiedad Intelectual. Bercovitz Rodríguez-Cano (coord.). Madrid: Editorial Tecnos.

- Maurel-Indart, H. (2014). Sobre el plagio. México: Fondo de Cultura Económica.

- Millé, A. (1994) “Música y electrónica: problemas de propiedad intelectual relacionados con la composición y ejecución musical con medios electrónicos". Boletín de Derecho de Autor Vol. XXVIII. No. 2..

- Mosser, K. (2008). "Cover songs»: Ambiguity, multivalence, polysemy". Popular Musicology Online, No. 2..

- Nieto, J. (1996). Música para la imagen. La influencia secreta. Madrid: Editorial Iberautor.

- OMPI (1980). Glosario de derecho de autor y derechos conexos. Vol. 816. World intelectual property organization - Wipo. Organización Mundial de la Propiedad Intelectual. 0.

- Pérez Serrano, N. "El derecho moral de los autores". Anuario de Derecho Civil. Vol. 2. No. 1 (1949):7 - 27.

- Randel, M (1984). Diccionario Harvard de música. México: Editorial Diana.

- Rivero Hernández, F. (1997). Comentarios a la Ley de Propiedad Intelectual, Coord. por Bercovitz Rodríguez-Cano, R. (2007). 
Comentario al artículo 21. Madrid: público en la propiedad intelectual". Los Editorial Tecnos.

- Rodríguez Tapia y Bondia Román. (2007). Comentario al artículo 9", Comentarios a la Ley de Propiedad Intelectual. Madrid: Editorial Thomson Civitas.

- Sánchez Aristi, R. (2005). La propiedad intelectual sobre las obras musicales. Granada: Editorial Comares.

- Suárez Lozano J. A. (2011). "El dominio derechos de propiedad individual en la obra audiovisual. O'callaghan (Coord.). Madrid: Editorial Dykinson.

- Witmer, R. y Marks, A. (2001). "Cover [cover version o cover recording]". The New Grove Dictionary of Music and Musicians. Sadie, Stanley \& Tyrrell John (Edits.). Londres: Macmillan. 